\title{
Papaya Ring Spot Virus (PRSV) as Influenced by the Length of Feeding Time of Aphids (Aphis gossypii)
}

\author{
Leilidyn Y. Zurbano ${ }^{* *}$ and Arce D. Bellere ${ }^{2}$ \\ 1Polytechnic University of the Philippines - Lopez, Quezon Philippines; leydenzurbano@yahoo.com \\ ${ }^{2}$ Central Bicol State University of Agriculture - Sipocot, Camarines Sur, Philippines; arcedbellere@gmail.com
}

\begin{abstract}
Background/Objectives: Aphids are known to be great vectors of Papaya Ring Spot Virus and its efficiency in disease transmission was observed based on the length of its feeding time on the healthy papaya plant. Methods/Statistical Analysis: The study was conducted at Bolo Sur, Sipocot, Camarines Sur and Red Lady Variety of Papaya was used as test crop. The study was composed of four treatments: T1 - control (without inoculants), T2 - the PRSV was inoculated for 30 seconds, T3 - 60 seconds and T4 - 90 seconds. The treatments were replicated three times and each replicate was inoculated with 10 aphids as vector. Appearance of symptoms, plant height and number of leaves were assessed for a period of 21 days for each of the treatments. Findings: Results showed that there are no significant differences on plant height among the treatments. However, significant differences on leaf number were observed where the healthy papaya plant had the most number of leaf, however, the length of feeding time of aphids did not had any significant result among the rest of the treatments. Furthermore, Symptoms of PRSV were observed 12 days after inoculation despite the varied feeding time of aphids. Application: Knowledge on the efficacy of PRSV transmission of aphids would be useful in assessing the crops to be grown with papaya and in formulating better fertilization and disease management.
\end{abstract}

Keywords: Aphis gosypii, Carica Papaya, Disease Transmission, Non-persistent Manner, Papaya Ring Spot Virus

\section{Introduction}

Papaya (Carica papaya L.), an important fruit crop of Philippines and is extensively cultivated. Mainly intended for the domestic market, papaya is predominantly grown by small-scale peasant producers with very little application of inputs. The average yield is low at only about 14 metric tons per hectare as compared to 70 to 90 metric tons per hectare under commercial/plantation scale production. Yield levels are also variable due primarily to insects, diseases and viruses. Even yields of the newly developed high-yielding papaya varieties have remained low due to the growing incidence of the Papaya Ring Spot Virus (PRSV).

PRSV was first detected in 1982 in the Southern Tagalog and Bicol Regions where it caused substantial damage to papaya orchards. The virus is believed to be widespread in Luzon and Visayas and is increasing in Mindanao where papayas for export are grown by multinational companies. PRV spread like a wildfire with 60 to $100 \%$ incidence and an estimated yield loss of about Php 6,309,000.00․․․

The PRSV affects all stages of plant growth from seedling to maturity ${ }^{2}$. PRSV is the most widespread and damaging viral disease affecting papaya production in many parts of the world. Plants of all ages are vulnerable to PRSV and affected plants become stunted leading to reduction in fruit set ${ }^{\underline{3}}$.

TPRSV (family Potyviridae, genus Potyvirus) is transmitted mechanically or by several species of aphids in a non-persistent manner. This type of transmission is generally characterized by a short Acquisition Access Period (AAP) of a few seconds to minutes, absence of a distinct latent period and a short Inoculation Access Period (IAP). Thus, the virus is acquired during brief exploratory probes in the process of host finding and

${ }^{*}$ Author for correspondence 
is transmitted to a healthy papaya plant within a few seconds to minutes. Aphids do not normally colonize papaya and natural transmission is reported to occur through transient aphid vectors.

Aphids are known to be great vectors of Papaya Ring Spot Virus. Hence, its efficiency in disease transmission was observed based on the length of its feeding time on the healthy papaya plant. Specifically, the study determined the occurrence of symptoms of the disease after inoculation and evaluated the effect of PRSV on plant height and number of leaf as compared to healthy plant.

The result will be of great importance to make an action for the prevention of PRSV. It will as well provide knowledge to the researchers on what are the span of time of inoculation and the occurrence of its signs and symptoms of PRSV. Moreover the result of this study can be utilized to prevent losses on papaya production due to PRSV and secure its profitability.

\section{Materials and Methods}

\subsection{Test Plant}

Red lady papaya variety from East West Seed Company was used as test crop. It is early, vigorous and highyielding hybrid papaya variety that has a potential yield of up to $120,000 \mathrm{~kg} / \mathrm{ha}$ in a two year productive life cycle. It is considered to be early maturing because it is harvestable at 8 to 9 months from sowing. Its semi-dwarf height begins to bear fruit at 50 to $80 \mathrm{~cm}$ height. It is said to be highly tolerant to PRSV.

\subsection{Experimental Design, Treatments and Layout}

This study was composed of four treatments: T1 - control (without inoculants), T2 - the PRSV was inoculated for 30 seconds, T3 - 60 seconds and T4 - 90 seconds. The treatments were replicated three times as shown in Figure 1. Each replicate was inoculated with 10 aphids as vector.

Analysis of Variance (ANOVA) for Completely Randomized Design (CRD) was used to determine if there were any significant differences on plant height and number of leaves for a period of 21 days for each of the treatments.

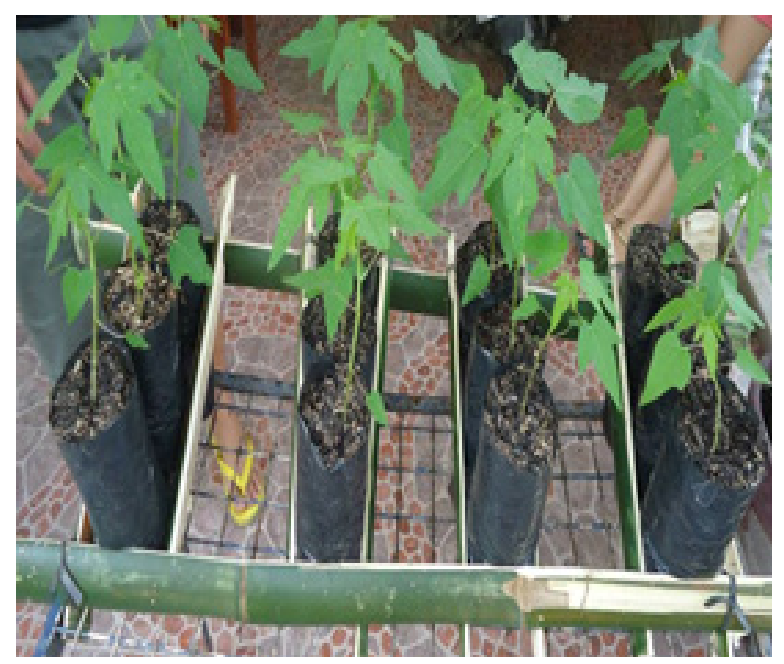

Figure 1. The experimental set-up

\subsection{Preparation of the Growing Substrates}

Growing substrates used in papaya were 60\% Carbonized Rice Hull (CRH), 20\% garden soil, 10\% vermicompost and $(10 \%)$ black river sand ${ }^{4}$. Vermicast was gathered in the vermi bin at Bolo Sur, Sipocot Camarines Sur. It is an organic fertilizer produced through the action of earthworms ${ }^{5}$. The substrate is composed of animal manure and chopped plant residues inoculated with African night crawler. The garden soil was gathered at Bolo Sur, Sipocot Camarines Sur and the topical loose dark brown layers were obtained. Black river sand was obtained from a reputable hardware distributor at Sipocot Camarines Sur and CRH was obtained from the farm. The substrate except vermicast were subjected to sterilization via frying pan; was mixed continuously until 2 hours and subsequently transferred in a clean area to facilitate cooling.

\subsection{Inoculation}

A papaya plant with ring spot symptoms was gathered from the field as source of inocula (Figure 2).

Aphids were gathered from infected papaya plants using soft paint brush. They were subjected for thirty minutes of fasting (Figure 3).

After fasting, the aphids were allowed to feed in the viral infected papaya for five minutes (Figure 4). Then, aphids were transferred to the healthy 7 leaf papaya seedling. Subsequently the aphids were removed; then 
observation for the signs and symptoms of the disease every 3 days for a period of twenty one days was done.
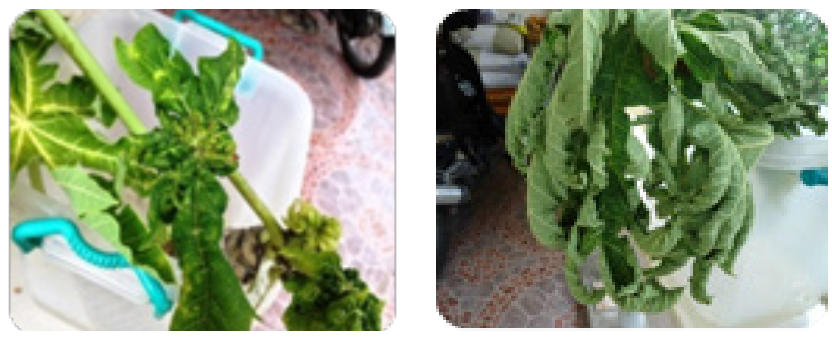

Figure 2. Papaya showing PRSV symptoms.

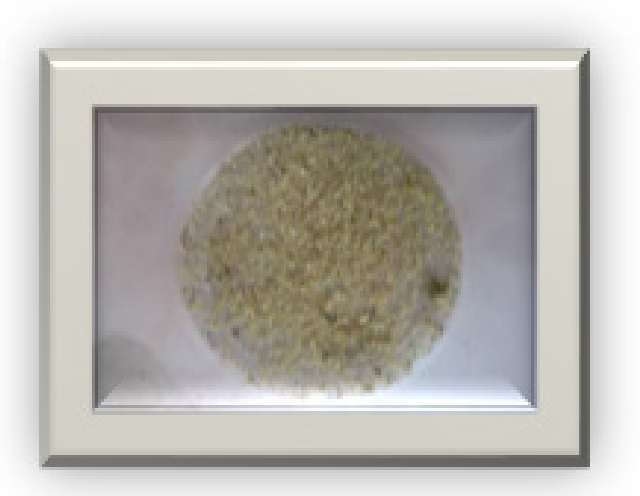

Figure 3. Aphids from infected papaya plant.
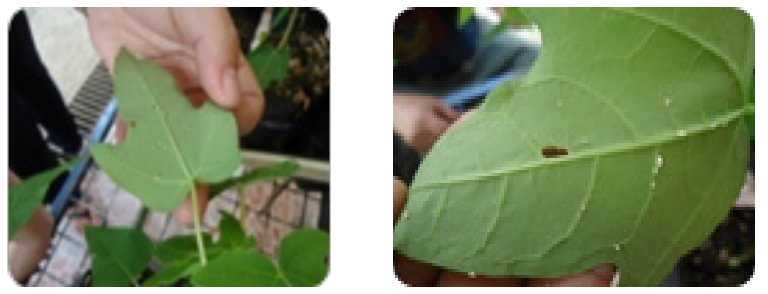

Figure 4. Healthy papaya plant inoculated with PRSV with aphids as vectors.

\subsection{Data Gathered}

\subsubsection{Plant Height before and after Inoculation}

Plant height refers to the linear distance from the bottom level of the shoot to the upper level of tip of the tallest leaf.

\subsubsection{Number of Leaves before and after Inoculation}

The number of leaves per plant was counted and recorded.

\subsubsection{Symptoms}

Symptoms of PRSV were observed every three days day for a period of 21 Days after Inoculation (DAI).

\section{Results and Discussion}

\subsection{Effects of PRSV on Growth Parameters}

Plant height of papaya was measured every 3 days after inoculation. Initial height was determined and increment on the height after 21 days was assessed. During the vegetative stage, the plant should already be $15-20 \mathrm{~cm}$ for 2 and $1 / 2$ months (www.plantogram.com/product/ papaya_red_lady/). The result of the study concurred with the expected typical growth which means that the plants are still growing normally without any visible symptoms of stunting.

Further test proved that no significant differences on the plant height increment were observed using varied treatments (Table 1). Though, it was mentioned in several studies that when the plant is infected at a young age, the plant might get stunted and will not be able to produce anymore. Trees that are infected at a young stage remain stunted and will not produce an economical crop ${ }^{3}$. It was also mentioned that when plants are infected at the seedling stage or within two months after planting, their fruits often will not reach maturity ${ }^{4}$. However, the observation of the PRSV symptoms on the study happened for only 21 days thus, no visible stunting was noticed.

The effect of Papaya Ring Spot Virus on plant growth and vigor varies considerably, depending on environmental conditions for growth ${ }^{6}$. Adverse environmental conditions such as seasonal drought or poor fertilization practices affect ring spot infected trees more severely than non-infected trees. Trees that are fertilized and irrigated regularly grow moderately well and produce fruit despite the presence of the disease. Stunting of all parts occurs in trees affected with the Papaya Ring Spot Virus under adverse environmental stress. Thus, it can be inferred that plant height of papaya in the study is not that affected because plants were not subjected to any adverse environmental condition.

Number of leaves was also measured every 3 days after inoculation. Increment on the leaf number after 21 days was observed. Further test proved that significant differences on the leaf number increment were observed using varied treatments (Table 1). It shows that $\mathrm{T} 1 \mathrm{had}$ the most number of leaves as compared to Treatments 2 , 3 and 4.

However, treatment 4 showed that among T2 and T3 it has the most number of leaves. Thus, it can be inferred that regardless of the length of feeding time of aphids the 
effect on number of leaves would be evident. Moreover, it can also be deduced that somehow, the number of leaves were affected by PRSV since among the treatments, only the control had the biggest increment. Based on the symptoms written in literature, leaves become yellow, and deformed with mosaic patterns.

The result of the study agreed with one author where he cited that when papaya is infected with ring spot virus, presence of very light irregular mottled areas on the underside of leaves, mottling of the whole leaf, severe chlorosis and premature abscission, cupping and severe distortion of leaves and diminished leaf production happen ${ }^{7}$.

Table 1. Plant height and leaf number 21 Days after Inoculation (DAI)

\begin{tabular}{|l|c|c|}
\hline Treatment & Plant Ht. $(\mathbf{c m})$ & Leaf Number \\
\hline $\begin{array}{l}\text { 1 (Control) - without } \\
\text { PRSV inoculants }\end{array}$ & $9.33^{\text {ns }}$ & $6.33 \mathrm{a}$ \\
\hline $\begin{array}{l}2-30 \text { sec of PRSV } \\
\text { inoculation }\end{array}$ & $8.00^{\text {ns }}$ & $3.67 \mathrm{ab}$ \\
\hline $\begin{array}{l}3-60 \text { sec of PRSV } \\
\text { inoculation }\end{array}$ & $10.17^{\text {ns }}$ & $3.00 \mathrm{~b}$ \\
\hline $\begin{array}{l}4-90 \text { sec of PRSV } \\
\text { inoculation }\end{array}$ & $10.17^{\text {ns }}$ & $2.67 \mathrm{~b}$ \\
\hline
\end{tabular}

* In a column the same letters indicate that the values are insignificantly different by Least Significance Difference Post Hoc Test $(\mathrm{P}>0.05)$

\subsection{PRSV Symptoms Observed Days after Inoculation}

The number of days after inoculation where symptoms of PRSV was observed was also recorded. Based on Table 2, it shows that from $3^{\text {rd }}$ until $9^{\text {th }}$ day of inoculation, no symptoms of PRSV were observed. It was only on the $12^{\text {th }}$ day, that symptoms of the virus were seen on Treatment 2,3 and 4 . In treatment 2 , it shows that only replicates 1 and 3 manifested PRSV symptoms while in treatment 3, only replicates 2 and 3 manifested PRSV symptoms. Subsequently, in treatment 4, all replicates exhibited PRSV symptoms. Fifteen days after inoculation, it shows that treatments 2, 3 and 4 and all of its replicates show off PRSV symptoms. Symptoms observed were leaf chlorosis and distortion. Thus, it can be surmised that regardless of the different feeding time of aphids, symptoms could appear even if it only fed for 30 seconds, PRSV could be transmitted. The symptoms of PRSV on the crop such as distorted leaf and yellow mosaic pattern was evident 18 DAI (Figure 5).

Moreover, the result of the study coincides with the study of - where the time necessary for plants to show leaf symptoms after inoculation varies from 9 to 39 days depending upon the climate. The symptoms coincide with the findings of ${ }^{-}$where mottling, chlorosis and distortion were evident on the leaves.

In addition, based on the study done by ${ }^{10}$ which focused on the inoculation of single and group aphid inoculation which used 5 aphids as vectors, symptoms appeared 30 days after with more plants exhibiting symptoms using group inoculation. Thus, it can be concluded based on this study that the more aphids used, the faster the manifestation of symptoms which happened in the study since 10 aphids were used and symptoms appeared 12 days after inoculation.

Plants inoculated during early summer do not develop even mild symptoms until 3 months after inoculation. During the winter months, however, symptoms are produced about 6 weeks after inoculation ${ }^{11}$.

Table 2. Signs and symptoms of PRSV observed Days after Inoculation

\begin{tabular}{|c|c|c|c|c|c|c|c|c|c|c|c|c|c|c|c|}
\hline \multirow{2}{*}{ Treatment } & \multirow{2}{*}{$\begin{array}{l}3 \\
\text { DAI } \\
\end{array}$} & \multirow{2}{*}{$\begin{array}{l}6 \\
\text { DAI } \\
\end{array}$} & \multirow{2}{*}{$\begin{array}{l}9 \\
\text { DAI } \\
\end{array}$} & \multicolumn{3}{|c|}{12 DAI } & \multicolumn{3}{|c|}{$15 \mathrm{DAI}$} & \multicolumn{3}{|c|}{$18 \mathrm{DAI}$} & \multicolumn{3}{|c|}{$21 \mathrm{DAI}$} \\
\hline & & & & R1 & R2 & R3 & R1 & R2 & R3 & R1 & R2 & R3 & R1 & R2 & R3 \\
\hline \multicolumn{16}{|l|}{1} \\
\hline \multicolumn{16}{|l|}{2} \\
\hline \multicolumn{16}{|l|}{3} \\
\hline 4 & & & & & & & & & & & & & & & \\
\hline
\end{tabular}

Legend: no symptoms observed

Symptoms observed 


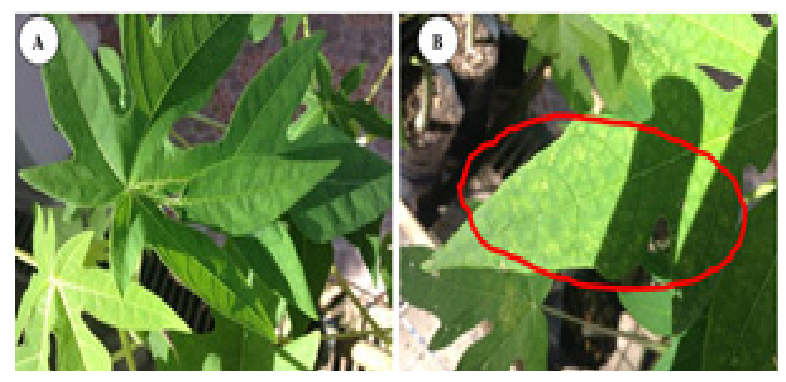

Figure 5. Eighteen days after inoculation A) distorted leaf and B) yellow mosaic pattern on papaya leaf.

\section{Conclusions}

With the significant result found in the study, it can be established that using aphids as vectors, PRSV could be transmitted easily in a non-persistent manner for the transfer of virus occurs in only a short period of time. Moreover, it can also be concluded that the appearance of symptoms appear for as early as two weeks with the use of group aphid inoculation. Furthermore, the effect of PRSV on plant height could not yet be established since observation happens only in a short period of time. On the other hand, significant differences were noted on the leaf number, showing that the healthy plant had the most number of leaf as compared to those inoculated with PRSV, thus diminished leaf production would be evident if plant is affected at a very young age. Daily monitoring and observation of the symptoms of PRSV in papaya, removal of other host plant of aphids and PRSV and better fertilization, management and care should be done in order for the papaya infected with PRSV to still be prolific.

\section{References}

1. Opina OS. Studies on a new virus disease of papaya in the Philippines. Food and Fertilizers Technology Center Bull. 1986; 33:1-16.

2. The Agricultural Biotechnology Support Project II (ABSPII). 2010. http://www.isaaa.org/programs/supportprojects/ abspii/

3. Gonsalves D. Control of papaya ringspot virus in papaya: A case study. Annual Review of Phytopathology. 1998; 36:415-37. PMid: 15012507. https://doi.org/10.1146/ annurev.phyto.36.1.415

4. Off Season discounts. 2008. https://www.tripadvisor.in/ ShowTopic-g303881-i9231-k8151765-Off_Season_ discounts-Munnar_Idukki_District_Kerala.html

5. Papaya Ring Spot Virus. 2007. https://www.apsnet. org/edcenter/disandpath/viral/pdlessons/Pages/ PapayaRingspotvirus.aspx

6. Papaya Ring Spot Virus. Institute. 2019. https:// en.wikipedia.org/wiki/Papaya_ringspot_virus

7. Papaya Ring Spot Virus. 1984. https://www.cabi.org/isc/ datasheet $/ 45962$

8. Diseases of Papaya. 1965, https://scholarspace.manoa. hawaii.edu/handle/10125/14967? mode=full

9. Magdalita PM, Villegas VN, Pimentel RB, Bayot RG. Reaction of papaya (Carica papaya L.) and related carica species to ring spot virus. Philippine Crop Science Journal. 1988; 13(3):129-32.

10. Kalleshwaraswamy CM, Krishna Kumar NK. Transmission efficiency of Papaya Ring Spot Virus by three aphid species. Indian Phytopathology. 2008; 98(5):541-6. PMid: 18943221. https://doi.org/10.1094/PHYTO-98-5-0541

11. Papaya Ring Spot Virus. 2010. https://www.researchgate. net/publication/279370297_Papaya_Ringspot_Virus 